\title{
MICROINVASIVE BREAST CARCINOMA: AN ANALYSIS FROM TEN SENONETWORK ITALIA BREAST CENTRES
}

\author{
Leopoldo Costarelli (1), Ettore Cianchetti (2), Fabio Corsi (3-4), Daniele Friedman (5), \\ Matteo Ghilli (6), MariaTeresa Lacaria (1), Lorenzo Menghini (7), Roberto Murgo (8), \\ Antonio Ponti (9), Stefano Rinaldi (10), Marco Rosselli del Turco (11), Mario Taffurelli (12), \\ Corrado Tinterri (13), Mariano Tomatis (9), Lucio Fortunato (1).
}

Affiliations

1. Breast Unit, San Giovanni-Addolorata Hospital, Rome, Italy

2. Breast Centre As102 Abruzzo, P.O. G. Bernabeo, Ortona, Italy

3. Surgery Department, Breast Unit, ICS Maugeri S.p.A., Pavia, Italy

4. Department of Biomedical and Clinical Sciences "L. Sacco", University of Milan, Milan, Italy

5. UO Chirurgia Senologica, Ospedale Policlinico San Martino, Genova, Italy

6. Breast Cancer Center, University Hospital of Pisa, Italy

7. Breast Unit Rimini-Sant'Arcangelo di Romagna, Italy

8. IRCCS, Ospedale Casa Sollievo della Sofferenza, San Giovanni Rotondo (FG), Italy

9. CPO Piemonte - SSD Epidemiologia Screening - CRPT, AOU Città della Salute e della Scienza di Torino, Italy

10. Chirurgia Senologica, Ospedale San Paolo, Bari, Italy

11. Senonetwok Italia Onlus, Florence, Italy

12. UOC di Chirurgia Generale e della Mammella Policlinico di Sant'Orsola - Università di Bologna, Italy

13. Breast Unit Humanitas Cancer Center, Rozzano, Italy

\section{ORIGINAL ARTICLE}

$\begin{array}{ll}\text { Leopoldo Costarelli } & \text { lcostarelli@hsangiovanni.roma.it } \\ \text { Antonio Ponti } & \text { antonio.ponti@cpo.it } \\ \text { Marco Rosselli del Turco } & \underline{\text { marco.rossellidt@gmail.com }} \\ \text { Maria Teresa Lacaria } & \underline{\text { lakymt@libero.it }} \\ \text { Mariano Tomatis } & \underline{\text { mariano.tomatis@gmail.com }} \\ \text { Fabio Corsi } & \underline{\text { fabio.corsi@ unimi.it }} \\ \text { Daniele Friedman } & \underline{\text { friedman@unige.it }} \\ \text { Roberto Murgo } & \underline{\text { romurgo@libero.it }} \\ \text { Lorenzo Menghini } & \underline{\text { lorenzo.menghini@auslromagna.it }} \\ \text { Matteo Ghilli } & \underline{\text { matteo.ghilli@gmail.com }} \\ \text { Ettore Cianchetti } & \underline{\text { solostefano } @ \text { unich.it }} \\ \text { Stefano Rinaldi } & \underline{\text { mario.taffurelli@ @aosp.bo.it }} \\ \text { Mario Taffurelli } & \underline{\text { corrado.tinterri@ cancercenter.humanitas.it }} \\ \text { Corrado Tinterri } & \underline{\text { fortunato@ hangiovanni.roma.it }} \\ \text { Lucio Fortunato } & \end{array}$


Address Correspondence to:

Lucio Fortunato, MD

Clinical Director, Breast Unit

Azienda Ospedaliera San Giovanni Addolorata

Via Amba Aradam 9, 00187 Rome, Italy

Tel: $+39 / 06 / 7705-6762$

Fax: +39/06/7705-5549

Email: 1fortunato@hsangiovanni.roma.it 


\section{ABSTRACT}

Background and Objectives: We studied a large series of ductal carcinoma in situ with microinvasion (MIDC) an infrequent disease whose diagnosis and management are not well defined.

Methods: 17,431 cases of breast carcinoma were treated between 2011 and 2016 by ten Italian Breast Units. Our analysis included diagnostic and clinic-pathological characteristics, surgical management, and the use of adjuvant therapies.

Results: 15,091 cases (86.6\%) were infiltrating carcinomas (IC), 2,107 (12.1\%) ductal carcinoma in situ (DCIS), and 233 (1.3\%) MIDC. Age at diagnosis did not differ between DCIS and MIDC. MIDC were usually larger and expressed more frequently biologically aggressive features (higher Ki67 values, hormone receptor negativity and HER2/neu over-expression) $(\mathrm{p}<0.01)$. Axillary lymph nodes were involved in 25 MIDC cases (12\%), but >3 lymph nodes were involved in two cases only (1\%). At multivariable analysis, only lymphovascular invasion (LVI) was associated with lymph node status ( $\mathrm{p}<0.01$ ). Hormone therapy was prescribed in 388/1,462 DCIS cases (26.5\%), in 84/200 MIDC cases $(42 \%)$, and in $11,086 / 14,188$ IC cases $(84.7 \%)(\mathrm{p}<0.01)$. Chemotherapy was administered in 28/190 MIDC cases (14.7\%), and in 4,080/11,548 IC cases $(35.3 \%)(\mathrm{p}<0.001)$.

Conclusions: This is one of the largest studies of MIDC reported in the literature. Approximately $10 \%$ of DCIS harbor one or more foci of MIDC, and the latter often expresses aggressive biological features. LVI is a predictor of axillary node involvement, but this is infrequent and usually limited. Conservative surgery is performed less often than in DCIS, and adjuvant chemotherapy is less frequently utilized compared to IC.

Keywords: Microinvasive Breast Cancer, DCIS, Breast Cancer, Axillary Lymph Node 


\section{INTRODUCTION}

Over the past two decades, the widespread use of mammographic screening for breast carcinoma has dramatically increased the diagnosis of ductal carcinoma in situ (DCIS) [1]. In the United States, DCIS incidence rose from 1.87 per 100,000 in 1973-1975 to 32.5 per 100,000 in 2004, particularly in women older than 50 years. While in the past DCIS accounted for fewer than $5 \%$ of breast cancers, it currently represents $20 \%-30 \%$ of cases, and $30 \%-50 \%$ of all mammographically detected cancers. [2].

Similarly, improvements of mammographic screening programs have contributed to a more frequent diagnosis of small invasive breast cancers in recent years. A particular subset of such malignancies is represented by microinvasive ductal carcinoma (MIDC), defined as a stromal invasion smaller than $1 \mathrm{~mm}$ in diameter [3]. MIDC accounts for about $1 \%$ of all breast cancer cases, and while the vast majority of MIDC are found within DCIS lesions, the former is associated with DCIS in approximately $5-10 \%$ of cases [4].

The fifth edition of the AJCC Cancer Staging Manual published in 1997 was the first to recognize a specific T substage for MIDC, formally reported as pT1mic [5].

It is well recognized that DCIS is not a single disease, as it shows several different biological behaviors based on histological features, hormone receptor status, growth factor receptor status, proliferation rate, and probably genetic signature [6]. The biology of MIDC is also not well understood, and both the significance of microinvasion and its clinical management are controversial. Usually, pathologic features of MIDC show adverse prognostic factors compared to DCIS [7,8,9], and the former is typically associated with larger DCIS tumors, whose histology exhibits high-grade features and comedo patterns [10]. However, its true metastatic potential is still unclear [11].

Due to the rare diagnosis of MIDC, its infrequent inclusion in large published cohorts of patients and its unclear clinical behavior, very little evidence is available to guide management of this disease. Thus far, few large, multicentric experiences with MIDC have been published in the literature [4].

The aim of this study is to describe a large, multicentric, series of MIDC with a focus on diagnosis, pathological features and treatment, to compare MIDC with DCIS and IC, and to study the relationship of MIDC characteristics with lymph node involvement.

\section{MATERIALS AND METHODS}


Approval by the Institutional Review Boards of the participating Institutions was waived because data was de-identified and analyzed in aggregate.

Data were obtained from ten prospectively maintained databases of Breast Centers associated with Senonetwork Italia (www.senonetwork.it), a non for profit organization aiming at building a network of Italian Breast Centers and promote quality of care. All patients were treated between 2011 and 2016. For data recording all Centers used DataBreast (www.databreast.com), implemented for the control of the quality indicators [12] recommended by Eusoma (European Society of Breast Cancer Specialists).

The following information were available: age at diagnosis, mammographic BIRADS score, presence or absence of microcalcifications and mammographic pattern (architectural pattern, irregular opacity of the breast tissue, mass diameter, architectural distortion and focal asymmetry), ultrasound features, clinical features, results and diagnostic testing including fine needle aspiration cytology (FNAC) and needle biopsy, histologic type of DCIS, presence or absence of necrosis, in situ component of invasive carcinoma, Grade of in situ ad invasive cancer, lymph node status, estrogen receptor (ER), progesteron receptor (PgR), HER2/neu status, Ki-67 value, surgical treatment of the breast and axilla, type of adjuvant treatment including chemotherapy, radiotherapy and hormonal therapy. The dataset did not specify for the type of needle biopsy (either core or vacuum-assisted biopsy), nor for the gauge of the needle used to obtain the samples.

Diagnostic features at ultrasound and mammography were classified according to the method proposed by the American College of Radiology [13], and FNAC and FNAB results were classified according to the European Guideline of Quality Assurance in Breast Cancer Screening and Diagnosis (European Commission 2006) [14] .

Generally, immunohistochemistry studies were performed on surgical specimens, and in case of MIDC the most representative portion was chosen.

We primarily analyzed the entire cohort of MIDC cases, describing baseline characteristics, pathologic features, and cancer subtype distribution, in order to find any specific identifying profile of this rare tumor. Than we compared this group with DCIS and IC cases.

Finally, two of the Authors (LC and MTL) searched on Medline/PubMed (www.ncbi.nlm.nih.gov) the literature on MIBC (search for "microinvasive breast carcinoma" or "microinvasive breast cancer"), with no restrictions on the date of publication. The relevant papers were selected by reading 
the abstracts and the full text. The references of the selected papers were then used to identify additional relevant studies.

\section{Statistical Analysis}

Statistical analysis was performed with the statistical package R. Student's $t$-test for significance between means and binomial analyses using Pearson's $\chi^{2}$ test were performed. Characteristics of cases in relation to lymph nodes status were studied by multivariable analysis. All analyses have excluded missing values, which are documented separately.

The study was conducted according to the principles laid down in the declaration of Helsinki. Cases were de-identified and data was analyzed in aggregate.

\section{RESULTS}

We analyzed 17,431 breast carcinoma of which 15,091 (86.6\%) were classified as IC, 2,107 (12.1\%) as DCIS, and $233(1.3 \%)$ as MIDC.

Mean age at diagnosis of DCIS (57,8 \pm 12.2 years) and MIDC (56.4 \pm 13 years) did not differ, while it was higher in case of IC $(60.6 \pm 13,7$ years) $(\mathrm{p}<0.001)$. Age less than 50 years was observed in 82/233 MIDC cases $(35.2 \%)$, and in 3,813/15,091 IC cases $(25.4 \%, \mathrm{p}<0.05)$. There were no further statistically significant differences between age groups.

Diagnostic features of the three groups are described in Table 1. 
Table 1 - Diagnostic features

\begin{tabular}{|c|c|c|c|c|c|}
\hline & $\begin{array}{c}\text { DCIS } \\
(n=1,705)\end{array}$ & $\begin{array}{l}\text { MIDC } \\
(n=202)\end{array}$ & $\begin{array}{c}\text { IC } \\
(n=12,153)\end{array}$ & $\begin{array}{c}p \\
\text { MIDC vs. IC }\end{array}$ & $\begin{array}{c}p \\
\text { MIDC vs. DCIS }\end{array}$ \\
\hline R1 & $95(5.6 \%)$ & $15(7.4 \%)$ & $927(7.6 \%)$ & & \\
\hline $\mathbf{R 2}$ & $32(1.9 \%)$ & $6(3 \%)$ & $173(1.4 \%)$ & & \\
\hline $\mathbf{R 3}$ & $332(19.5 \%)$ & $19(9.4 \%)$ & $1,038(8.5 \%)$ & & \\
\hline R4 & $1,076(63.1 \%)$ & $134(66.3 \%)$ & $7,161(58.9 \%)$ & & \\
\hline $\mathbf{R 5}$ & $170(10 \%)$ & $28(13.9 \%)$ & $2,854(23.5 \%)$ & & \\
\hline R4+R5 & $1,246(73.1 \%)$ & $162(80.2 \%)$ & $10,015(82.4 \%)$ & n.s. & $<0.001$ \\
\hline & $\begin{array}{c}\text { DCIS } \\
(n=1480)\end{array}$ & $\begin{array}{l}\text { MIDC } \\
(n=187)\end{array}$ & $\begin{array}{c}\text { IC } \\
(n=14,696)\end{array}$ & & \\
\hline US1 & $405(27.4 \%)$ & $26(13.9 \%)$ & $745(2.4 \%)$ & & \\
\hline US2 & $125(8.4 \%)$ & $4(2.1 \%)$ & $273(1.1 \%)$ & & \\
\hline US3 & $196(13.2 \%)$ & $15(8 \%)$ & $1,058(6.5 \%)$ & & \\
\hline US4 & $619(41.8 \%)$ & $109(58.3 \%)$ & $8,297(58.1 \%)$ & & \\
\hline US5 & $135(9.1 \%)$ & $33(17.6 \%)$ & $4,323(31.9 \%)$ & & \\
\hline US4+US5 & $754(50.9 \%)$ & $142(75.9 \%)$ & $12,620(90 \%)$ & $<0.001$ & n.s. \\
\hline FNAC & $\begin{array}{c}\text { DCIS } \\
(n=355)\end{array}$ & $\begin{array}{l}\text { MIDC } \\
(n=44)\end{array}$ & $\begin{array}{c}\text { IC } \\
(n=5557)\end{array}$ & & \\
\hline C1 & $33(9.3 \%)$ & $2(4.5 \%)$ & $302(5.4 \%)$ & & \\
\hline $\mathrm{C2}$ & $22(6.2 \%)$ & 0 & $70(1.3 \%)$ & & \\
\hline C3 & $60(16.9 \%)$ & $3(6.8 \%)$ & $256(4.6 \%)$ & & \\
\hline C4 & $80(22.5 \%)$ & $4(9.1 \%)$ & $916(16.5 \%)$ & & \\
\hline C5 & $160(45.1 \%)$ & $35(79.5 \%)$ & $4,013(72.2 \%)$ & & \\
\hline $\mathrm{C4}+\mathrm{C5}$ & $240(67.6 \%)$ & $39(88.6 \%)$ & $4,929(88.7 \%)$ & $<0.001$ & n.s. \\
\hline Needle Biopsy & $\begin{array}{c}\text { DCIS } \\
(n=1675)\end{array}$ & $\begin{array}{l}\text { MIDC } \\
(n=195)\end{array}$ & $\begin{array}{c}\text { IC } \\
(n=10,353)\end{array}$ & & \\
\hline B1 & $22(1.8 \%)$ & $3(1.5 \%)$ & $93(0.9 \%)$ & & \\
\hline B2 & $48(2.8 \%)$ & $2(1 \%)$ & $93(0.9 \%)$ & & \\
\hline B3 & $146(8.7 \%)$ & $3(1.5 \%)$ & $113(1.1 \%)$ & & \\
\hline B4 & $51(3 \%)$ & $4(2.1 \%)$ & $144(1.4 \%)$ & & \\
\hline B5 & $1,418(84.2 \%)$ & $183(93,8 \%)$ & $9,910(95.7 \%)$ & & \\
\hline B4+B5 & $1,469(87.2 \%)$ & $187(95.9 \%)$ & $10,054(97.1 \%)$ & n.s. & $<0.001$ \\
\hline
\end{tabular}

We found that 45/187 MIDC cases (24\%) were not diagnosed by US or showed a low index of suspicion (US1-2-3) while this occurred in 726/1,480 DCIS cases (49\%) and in 2,076/14,696 IC cases 
$(14 \%)(\mathrm{p}<0.01)$. Similarly, mammographic findings highly suggestive of malignancy were less frequent in DCIS than in the other two groups $(\mathrm{p}<0.001)$.

Twenty-seven percent of DCIS, $19.8 \%$ of MIDC and 17.5\% of IC showed mammographic features interpreted as benign (R1-2) or probably benign (R3). Microcalcifications were detected in 1,264/1,561 (81\%) of DCIS cases, in 141/183 MIDC cases (77.9\%), and only in 2,851/10,251 IC cases $(27.8 \%)(\mathrm{p}<0.01)$.

Core biopsy was considerably more sensitive than FNAC (respectively 13.3\% vs. 32,4\% of DCIS, $4 \%$ vs. $11.3 \%$ of MIDC and $2.9 \%$ vs. $11.3 \%$ of IC were diagnosed as inadequate, benign or probably benign) $(\mathrm{p}<0.001)$.

The mean tumor diameter of MIDC (28,2 $\pm 17 \mathrm{~mm})$ (including the in situ and infiltrating components) was significantly higher compared to that of DCIS $(19,4 \pm 12 \mathrm{~mm})$ and IC $(22 \pm 16 \mathrm{~mm})(\mathrm{p}<0.05)$.

There was no statistically significant difference in the pattern of growth of the intraductal component of DCIS and MIDC groups.

The presence of necrosis was more frequent in the MIDC group $(61 / 119 ; 51.3 \%)$, than in DCIS $(301 / 914 ; 32.9 \%)$ or in IC group $(802 / 3758 ; 21.3 \%)(\mathrm{p}<0.01)$.

High tumor grade of the infiltrating component was more frequently in MIDC (49\%) than in IC $(28.4 \%)(\mathrm{p}<0.001)$.

Lymphovascular invasion (LVI) was found in 10/203 (4.9\%) cases of MIDC.

Table 2 shows the results of immunohistochemistry results, comparing expression of ER, PgR, HER2/neu and Ki67. 
Table 2 - Immunohistochemistry

\begin{tabular}{|c|c|c|c|c|c|}
\hline & DCIS & MIDC & IC & $\begin{array}{c}\text { p } \\
\text { MIDC vs IC }\end{array}$ & $\begin{array}{c}\text { p } \\
\text { MIDC vs DCIS }\end{array}$ \\
\hline ER+ & $\begin{array}{c}920 / 1,142 \\
(80.6 \%)\end{array}$ & $\begin{array}{l}131 / 204 \\
(64.2 \%)\end{array}$ & $\begin{array}{c}12,938 / 14,651 \\
(88.3 \%)\end{array}$ & $<0.001$ & $<0.001$ \\
\hline PgR+ & $\begin{array}{c}799 / 1,130 \\
(70.7 \%)\end{array}$ & $\begin{array}{l}102 / 203 \\
(50.2 \%)\end{array}$ & $\begin{array}{c}11,361 / 14,612 \\
(77.8 \%)\end{array}$ & $<0.001$ & $<0.001$ \\
\hline HER2/neu+ & & $\begin{array}{l}49 / 129 \\
(38 \%)\end{array}$ & $\begin{array}{c}943 / 9,112 \\
(10.3 \%)\end{array}$ & $<0.001$ & \\
\hline $\begin{array}{l}\text { HER2/neu } \\
\text { equivocal }\end{array}$ & & $\begin{array}{l}9 / 129 \\
(7 \%)\end{array}$ & $\begin{array}{c}1,269 / 9,112 \\
(13.9 \%)\end{array}$ & & \\
\hline Ki67> 15\% & $\begin{array}{l}103 / 243 \\
(42.4 \%)\end{array}$ & $\begin{array}{l}80 / 149 \\
(53.7 \%)\end{array}$ & $\begin{array}{c}5,262 / 10,270 \\
(51.2 \%)\end{array}$ & n.s. & $<0.005$ \\
\hline
\end{tabular}

In the MIDC group Sentinel Lymph Node (SLN) biopsy was performed in 90.6\% (184/203) of cases, SLN biopsy associated with axillary dissection in 6,4\% (13/203) and an axillary dissection alone was chosen in $3 \%(6 / 203)$ of cases.

Nodal status of the three groups are described in Table 3.

\section{Table 3 - Lymph node status}

\begin{tabular}{|l|c|c|c|c|c|}
\hline & $\begin{array}{c}\text { DCIS } \\
(\mathbf{n = 2 , 1 0 7 )}\end{array}$ & $\begin{array}{c}\text { MIDC } \\
(\mathbf{n = 2 0 3})\end{array}$ & $\begin{array}{c}\text { IC } \\
(\mathbf{n = 1 3 , 9 8 4})\end{array}$ & $\begin{array}{c}\mathbf{p} \\
\text { MIDC vs IC }\end{array}$ & $\begin{array}{c}\text { p } \\
\text { MIDC vs DCIS }\end{array}$ \\
\hline Micrometastasis & 0 & $5(2.4 \%)$ & $420(3 \%)$ & & \\
\hline $\begin{array}{l}\mathbf{1 - 3} \text { lymph nodes } \\
\text { macrometastasis }\end{array}$ & 0 & $18(8.8 \%)$ & $3,125(22.3 \%)$ & & \\
\hline $\begin{array}{l}\geq \mathbf{4} \text { lymph nodes } \\
\text { macrometastasis }\end{array}$ & 0 & $2(1 \%)$ & $1,587(11.3 \%)$ & & \\
\hline $\begin{array}{l}\text { Total lymph node } \\
\text { involvement }\end{array}$ & 0 & $25(12.2 \%)$ & $5,132(36.6 \%)$ & $<\mathbf{0 . 0 0 1}$ & $<\mathbf{0 . 0 0 1}$ \\
\hline
\end{tabular}

Among microinvasive cancers, only LVI was associated with lymph node status, both at univariable and multivariable analysis (Table 4). 
Table 4 - Multivariable analysis of characteristics potentially associated with lymph node status in MIDC

\begin{tabular}{|c|c|c|c|c|c|c|c|}
\hline & & \multirow{2}{*}{$\begin{array}{c}\text { Total } \\
203 \\
\end{array}$} & \multirow{2}{*}{$\begin{array}{c}\% \mathrm{~N}+ \\
12.3 \%\end{array}$} & \multicolumn{2}{|c|}{ Univariable } & \multicolumn{2}{|c|}{ Multivariable } \\
\hline & & & & OR & p-value & OR & p-value \\
\hline \multirow{2}{*}{ Grade invasive } & $1-2$ & 84 & $11.9 \%$ & ref. & & ref. & \\
\hline & 3 & 86 & $11.6 \%$ & 0.97 & 0.96 & 0.92 & 0.90 \\
\hline \multirow{2}{*}{ G DCIS } & $1-2$ & 65 & $12.3 \%$ & ref. & & ref. & \\
\hline & 3 & 109 & $13.8 \%$ & 1.14 & 0.78 & 1.37 & 0.63 \\
\hline \multirow{2}{*}{ ER } & Negative & 67 & $9.0 \%$ & ref. & & ref. & \\
\hline & Positive & 114 & $15.8 \%$ & 1.91 & 0.20 & 1.93 & 0.36 \\
\hline \multirow{2}{*}{ PgR } & Negative & 94 & $10.6 \%$ & ref. & & ref. & \\
\hline & Positive & 87 & $16.1 \%$ & 1.61 & 0.28 & 1.61 & 0.47 \\
\hline \multirow{2}{*}{ Ki67 } & $\leq 15 \%$ & 61 & $9.8 \%$ & ref. & & ref. & \\
\hline & $>15 \%$ & 74 & $13.5 \%$ & 1.43 & 0.51 & $1, .85$ & 0.33 \\
\hline \multirow{2}{*}{ HER2/neu } & $0 / 1+$ & 66 & $10.6 \%$ & ref. & & ref. & \\
\hline & $2+/ 3+$ & 54 & $13.0 \%$ & 1.26 & 0.69 & 1.27 & 0.71 \\
\hline \multirow{2}{*}{ LVI } & No & 149 & $10.1 \%$ & ref. & & ref. & \\
\hline & Yes & 9 & $55.6 \%$ & 11.17 & $<0,01$ & 24.04 & $<0.01$ \\
\hline \multirow{2}{*}{ Size } & $\leq 50 \mathrm{~mm}$ & 101 & $11.9 \%$ & ref. & & ref. & \\
\hline & $>50 \mathrm{~mm}$ & 15 & $13.3 \%$ & 1.14 & 0.87 & 0.46 & 0.471 \\
\hline
\end{tabular}

Table 5 reports the data on surgical management and post-operative therapies.

Table 5- Surgical management and post-operative therapies

\begin{tabular}{|c|c|c|c|c|c|}
\hline & DCIS & MIDC & IC & $\begin{array}{c}\text { p } \\
\text { MIDC vs IC }\end{array}$ & $\begin{array}{c}p \\
\text { MIDC vs DCIS }\end{array}$ \\
\hline $\begin{array}{l}\text { Breast conservative } \\
\text { surgery }(\mathrm{BCS})\end{array}$ & $\begin{array}{c}1,526 / 2057 \\
(74.2 \%)\end{array}$ & $\begin{array}{l}132 / 232 \\
(56.9 \%)\end{array}$ & $\begin{array}{c}10,258 / 14,906 \\
(68.8 \%)\end{array}$ & $<0.01$ & $<0.01$ \\
\hline $\begin{array}{l}\text { Radiotherapy post- } \\
\text { BCS }\end{array}$ & $\begin{array}{c}959 / 1,272 \\
(75.4 \%)\end{array}$ & $\begin{array}{l}101 / 121 \\
(83.5 \%)\end{array}$ & $\begin{array}{c}8,160 / 9,028 \\
(90.4 \%)\end{array}$ & $<0.05$ & $<0.05$ \\
\hline Hormonal therapy & $\begin{array}{c}388 / 1462 \\
(26.5 \%)\end{array}$ & $\begin{array}{l}84 / 200 \\
(42 \%)\end{array}$ & $\begin{array}{c}10,614 / 12,526 \\
(84.7 \%)\end{array}$ & $<0.01$ & $<0.01$ \\
\hline Chemotherapy & & $\begin{array}{l}28 / 190 \\
(14.7 \%)\end{array}$ & $\begin{array}{c}4,080 / 11,548 \\
(35.3 \%)\end{array}$ & $<0.01$ & \\
\hline
\end{tabular}


Treatment with hormone therapy was performed in 388 DCIS cases (26.5\%), 84 MIDC cases (42\%) and in 10,614 IC cases $(84.7 \%)(\mathrm{p}<0.01)$. The difference is largely explained by the different expression of ER (64.2\% of the MIDC and $88.3 \%$ of the IC were positive for ER).

\section{DISCUSSION}

This observational retrospective study of prospectively collected data was based on a multicenter series from ten Italian Breast Centers. It is one the largest study on MIDC to date.

In our experience MIDC represents roughly $1 \%$ of all breast carcinomas, a finding consistent with a large sample of 8,863 patients from the SEER database [4].

The mean age of patients with MIDC was similar to those with DCIS, while it was significantly higher in women with IC. This, apart from the larger sample size, may be explained by earlier diagnosis of DCIS and MIDC compared to IC, and the difference (3-4 years) has been hypothesized as the possible latency period for the development of an invasive carcinoma [4].

While both mammography and US proved to be for diagnosis in all the three groups, MIDC was statistically more often diagnosed with mammography compared to DCIS, and less often than IC by US.

Radiological features were quite different in DCIS and MIDC compared to IC. In the former group, microcalcifications represent the major diagnostic pattern ( $80 \%$ of cases), while in the latter an irregular opacity and architectural distortion were most frequently recorded.

Our experience confirms that MIDC generally shows more serious biological features compared with IC, as it is more frequently ER/PgR negative and HER2/neu positive.

Yang et al. [10] reported high nuclear grade and predominant comedo subtype of DCIS components in $57.1 \%$ and $46.4 \%$ in their experience, while $86 \%$ of their patients showed DCIS with necrosis.

Lack of expression of ER is more frequent in MIDC than in DCIS or IC, and in accordance to our findings this is reported in $22-33 \%$ of cases in other studies [4,7].

Also similar to our findings, other groups reported a rate of HER2/neu overexpression in MIDC in about one third of cases [4,7,8], while others registered an incidence as high as 49\% [15], and in their experience this was not associated with higher recurrence rate. Both high grade and HER2/neu+ MIDC or DCIS cases were more likely to be detected at breast cancer screening using mammography, 
probably because frequently show comedonecrosis, eventually associated with pleomorphic microcalcifications. In our series, necrosis was present in over $50 \%$ of MIDC.

It is not clear if these differences can be explained with an intrinsic biological aggressiveness of MIDC or with the fact that low-grade MIDC and DCIS are possibly underdiagnosed, because conventional methods of imaging is less sensitive in these cases.

Studies have shown that only a fraction of women with DCIS alone later progress to invasive cancer [16]. It is possible that small, low-grade lesions escape any clinical investigation, including mammography. Sensitivity of mammography screening for detection of DCIS and MIDC is high; this fact has the potential effect of causing overestimation of the ability of mammography to detect in situ disease, so that hypothetical sensitivity for detecting DCIS would be biased upward [2].

FNAB is highly preferred for diagnosis of MIDC and DCIS, and in our experience it shows a false negative rate of about one third compared to that of FNAC (6\% vs. $20 \%$ ).

In this study, lymph node involvement was $12 \%$ in MIDC cases, approximately one third of what we found in IC cases. Although the reported incidence of lymph node metastasis in the literature ranges from $0 \%$ to $20 \%$ [17], in most reports it is lower than $10 \%$ [11], and it is $7.6 \%$ in the SEER series on 8,863 patients [4]. A report from the European Institute of Oncology demonstrated that while metastases in the sentinel lymph node were detected in 4 of 41 patients (9.7\%), two of these had only micrometastasis and after axillary node dissections this was the only positive node in three patients [18]. Zavagno et al. [19] found four positive patients out of 43 cases (9.3\%), one of which was a micrometastasis. In a large serie of Matsen et al. [9] micrometastases were found in $6.3 \%$ and macrometastasis in $1.4 \%$ of cases, and no difference in SLN involvement was reported according to the number of microinvasive foci. In one study [20], patients with MIDC were divided into two groups according to the type of microinvasion (infiltration of the stroma by single cells, type 1 - or clusters, type 2), and the incidence of axillary lymph node metastasis was $0 \%$ and $10,1 \%$, respectively.

We confirm that multiple involvement of the axillary lymph nodes ( $\geq 4$ lymph nodes) is a rare event in MIDC (1\%), and therefore SLN biopsy alone might well be an appropriate treatment in this setting if patients present with clinically negative axillary lymph nodes [11]. Similar to what described in other series [9,38], using multivariable analysis, our experience shows that LVI was the only statistically significant variable associated with the lymph node status. 
In addition, similar to other reports [9,15], surgical treatment was quite different in MIDC in our study, as breast conservative surgery was performed in only $57 \%$ of cases of such cases compared to $69 \%$ of IC. This can be explained by the larger average size of MIDC, possibly due to extensive in situ component or multicentric disease.

Hormone therapy was used to a much lesser extent in MIDC than in IC (42\% vs $84 \%$ ), but this partly reflects the different positivity for ER in the two groups (64\% vs $82 \%)$. According to the NCCN Guidelines [23], tamoxifen or aromatase inhibitors may be considered as a strategy to reduce the risk of ipsilateral breast cancer recurrence in women with ER-positive DCIS and MIDC treated with breast-conserving therapy.

Adjuvant chemotherapy was prescribed in our experience in $14.7 \%$ of patients with MIDC, but this can range in the literature from 4 to $15 \%[9,15]$.

Wang et al. [16] analyzed prognosis of MIDC and DCIS, and in a multivariable analysis found that microinvasion was an independent prognostic factor for OS (HR, 1.2; $<<0.001)$. The 10-year cancerspecific mortality rate was $1.5 \%$ in DCIS and 4\% in MIDC (HR, 2.8; $<<0.001$ ), while the 20-year cancer-specific mortality rate was $4 \%$ in DCIS and 10\% in MIDC (HR, 2.5; p < 0.001).

However, one group stated HER2/neu overexpression, although prevalent, is not significantly associated with recurrence [15]. Furthermore, prognosis of MIDC seems to be independent of SLN status, as all 18/414 patients who suffered recurrence in the MSKCC study had a negative SLN status, for an overall 5-year recurrence-free proportion of 95.9\% [9].

Table 6 summarizes data from the available literature on MIDC. 
Tab. 6 - Results of a literature search on published MIDC series

\begin{tabular}{|c|c|c|c|c|c|c|c|c|c|c|c|c|}
\hline AUTHOR & Years & $\mathbf{N}$ & $\begin{array}{c}\mathrm{Ag} \\
\mathrm{e}\end{array}$ & $\begin{array}{c}\text { Grade } \\
\text { G3 }\end{array}$ & BCS & $\begin{array}{c}\text { pN1mi } \\
\text { or } \\
\text { pN0(i+) }\end{array}$ & $\begin{array}{c}\text { Macro } \\
\text { Metastasis }\end{array}$ & TLNI & ER+ & $\begin{array}{l}\text { HER2 } \\
\text { (neu)+ }\end{array}$ & ET & CHT \\
\hline Wang [4] & $\begin{array}{c}1990- \\
2012 \\
\end{array}$ & 8863 & & $44 \%$ & & & & $7.6 \%$ & $66 \%$ & $36 \%$ & & \\
\hline Mori [8] & $\begin{array}{l}2006- \\
2009\end{array}$ & 32 & 55 & $50 \%$ & & $3.6 \%$ & $3.6 \%$ & $7.2 \%$ & $30 \%$ & $59 \%$ & & \\
\hline $\begin{array}{l}\text { Matsen } \\
{[9]}\end{array}$ & $\begin{array}{l}1997- \\
2010 \\
\end{array}$ & 414 & 53 & $39 \%$ & $48 \%$ & $6.3 \%$ & $1.4 \%$ & $7,7 \%$ & $63 \%$ & $39 \%$ & $39 \%$ & $7.6 \%$ \\
\hline Yang [10] & $\begin{array}{l}1998- \\
2002\end{array}$ & 28 & 49 & $57 \%$ & & $0 \%$ & $0 \%$ & $0 \%$ & $61 \%$ & $36 \%$ & & \\
\hline $\begin{array}{l}\text { Margalit } \\
{[15]}\end{array}$ & $\begin{array}{l}1997- \\
2005\end{array}$ & 83 & 54 & $69 \%$ & $63 \%$ & $10 \%$ & 0 & $10 \%$ & $61 \%$ & $49 \%$ & $48 \%$ & $5 \%$ \\
\hline Intra [18] & $\begin{array}{l}1996- \\
2002\end{array}$ & 41 & 35 & $47 \%$ & $76 \%$ & $4.9 \%$ & $4.9 \%$ & $9.8 \%$ & $37 \%$ & & & \\
\hline $\begin{array}{l}\text { Zavagno } \\
\text { [19] }\end{array}$ & $\begin{array}{l}1999- \\
2004 \\
\end{array}$ & 43 & & $42 \%$ & $70 \%$ & $2.3 \%$ & $7 \%$ & $9.3 \%$ & & & & \\
\hline $\begin{array}{l}\text { De } \\
\text { Mascarel } \\
{[20]}\end{array}$ & $\begin{array}{l}1970- \\
1996\end{array}$ & 243 & & $54 \%$ & & & & $7 \%$ & & & & \\
\hline $\begin{array}{l}\text { Vieira } \\
\text { [21] }\end{array}$ & $\begin{array}{l}1993- \\
2006 \\
\end{array}$ & 21 & 56 & $76 \%$ & & & & & $75 \%$ & & & \\
\hline $\begin{array}{l}\text { Hai-Fei } \\
\text { Niu [24] }\end{array}$ & $\begin{array}{l}2006- \\
2013 \\
\end{array}$ & 108 & & & & & & $8.3 \%$ & $37 \%$ & $33 \%$ & & \\
\hline $\begin{array}{l}\text { Colleoni } \\
{[25]}\end{array}$ & $\begin{array}{l}1997- \\
2001\end{array}$ & 24 & & $50 \%$ & & & & & $62 \%$ & $36 \%$ & $32 \%$ & $4.5 \%$ \\
\hline Guth (26] & $\begin{array}{l}1991- \\
2006 \\
\end{array}$ & 59 & 57 & & & $4.5 \%$ & $6.8 \%$ & $\begin{array}{c}11.4 \\
\% \\
\end{array}$ & & & & \\
\hline $\begin{array}{l}\text { Zavotsky } \\
\text { [27] }\end{array}$ & $\begin{array}{l}1992- \\
1997 \\
\end{array}$ & 14 & & & $86 \%$ & & & $\begin{array}{c}14.3 \\
\% \\
\end{array}$ & & & & \\
\hline $\begin{array}{l}\text { Lillimoe } \\
{[28]}\end{array}$ & $\begin{array}{l}2001- \\
2015 \\
\end{array}$ & 276 & 57 & $70 \%$ & $42 \%$ & $1.2 \%$ & $0.4 \%$ & $1.6 \%$ & $85 \%$ & $39 \%$ & $43 \%$ & $4 \%$ \\
\hline Ko [29] & $\begin{array}{l}1989- \\
2008 \\
\end{array}$ & 293 & 47 & $29 \%$ & $37 \%$ & $6.1 \%$ & $1.4 \%$ & $7.5 \%$ & $43 \%$ & $58 \%$ & & \\
\hline $\begin{array}{l}\text { Prasad } \\
{[30]}\end{array}$ & $\begin{array}{l}1993- \\
1997 \\
\end{array}$ & 21 & 61 & $89 \%$ & $48 \%$ & $6.7 \%$ & $6.7 \%$ & $\begin{array}{c}13.4 \\
\% \\
\end{array}$ & $47 \%$ & $50 \%$ & & \\
\hline Silva [31] & $\begin{array}{l}2008- \\
2015 \\
\end{array}$ & 142 & 57 & & & & & $2.9 \%$ & $66 \%$ & & & \\
\hline Katz [32] & $\begin{array}{l}1998- \\
2003 \\
\end{array}$ & 21 & 55 & $33 \%$ & $67 \%$ & $4.8 \%$ & $4.8 \%$ & $9.6 \%$ & $67 \%$ & & & \\
\hline $\begin{array}{l}\text { Klauber- } \\
\text { De More } \\
{[33]}\end{array}$ & $\begin{array}{l}1997- \\
1999\end{array}$ & 38 & 51 & & & $6.2 \%$ & $3.1 \%$ & $9.4 \%$ & & & & \\
\hline Sakr [34] & $\begin{array}{l}1995- \\
2005 \\
\end{array}$ & 36 & 50 & $62 \%$ & $33 \%$ & $8.3 \%$ & $0 \%$ & $8.3 \%$ & & & & \\
\hline $\begin{array}{l}\text { Shatat } \\
{[35]}\end{array}$ & $\begin{array}{l}1998- \\
2012 \\
\end{array}$ & 40 & 58 & $65 \%$ & & $11.4 \%$ & $2.9 \%$ & $\begin{array}{c}14.3 \\
\% \\
\end{array}$ & $44 \%$ & $56 \%$ & & \\
\hline $\begin{array}{l}\text { Silver } \\
{[36]}\end{array}$ & $\begin{array}{c}1980- \\
1996 \\
\end{array}$ & 38 & 56 & & & $0 \%$ & $0 \%$ & $0 \%$ & & & & \\
\hline Kim [37] & $\begin{array}{l}2003- \\
2014 \\
\end{array}$ & 136 & $\begin{array}{c}50 . \\
2\end{array}$ & $69.2 \%$ & $\begin{array}{c}40.4 \\
\%\end{array}$ & $1.8 \%$ & $1.8 \%$ & $3.7 \%$ & $\begin{array}{c}45.6 \\
\% \\
\end{array}$ & $57 \%$ & $42 \%$ & \\
\hline $\begin{array}{l}\text { Orzalesi } \\
{[38]}\end{array}$ & $\begin{array}{l}1992- \\
2014 \\
\end{array}$ & 174 & & $36.8 \%$ & $\begin{array}{c}58.6 \\
\% \\
\end{array}$ & $10.3 \%$ & $4 \%$ & $\begin{array}{c}14.3 \\
\% \\
\end{array}$ & $\begin{array}{c}59.2 \\
\% \\
\end{array}$ & $73 \%$ & & \\
\hline $\begin{array}{l}\text { Current } \\
\text { study }\end{array}$ & $\begin{array}{l}2011- \\
2016 \\
\end{array}$ & 233 & $\begin{array}{c}56, \\
4 \\
\end{array}$ & $49 \%$ & $57 \%$ & $2.4 \%$ & $9.8 \%$ & $\begin{array}{c}12.2 \\
\% \\
\end{array}$ & $64 \%$ & $45 \%$ & $42 \%$ & $14,7 \%$ \\
\hline
\end{tabular}

Legend : BCS= Breast Conservation Surgery $\quad$ TLNI= Total Lymph Node Involvement $\quad$ LVI= Lymphovascular Invasion $\mathrm{ET}=$ Endocrine Therapy $\mathrm{CHT}=$ Chemotherapy 
There are several weaknesses of our study. First, we acknowledge that this is a retrospective analysis, although data were retrieved from prospective maintained databases. Second, some data is missing for several of the variables. Third, there was no centralized pathology review, and therefore diagnostic heterogeneity among different centers may have confounded the analysis of the available data. Finally, we did not have data regarding survival and disease-free survival, as this information was not available in the databases.

However, we believe that our report on a large experience from several dedicated Breast Centers contributes to a better understanding of the diagnostic issues of this disease, and provides an insight on the current management of MIDC.

\section{CONCLUSIONS}

MIDC is an infrequently disease, as it only represents approximately $1 \%$ of all breast cancers. It shows unfavorable biological features, like comedonecrosis, HER2/neu over-expression and negativity for hormone receptors, more frequently than IC.

The in situ component is usually of large size, and this explains the less frequent choice to perform BCS compared to IC. Lymph node involvement is never massive, but occurs $12 \%$ of cases in our study. Biopsy of the sole SLN may represent the only axillary treatment in most instances.

In our contemporary experiences, adjuvant hormonal therapy and adjuvant chemotherapy were prescribed in $42 \%$ and in $14 \%$ of patients with MIDC, respectively. Further studies are needed to better clarify this disease.

\section{Conflict of Interest}

Declarations of interest: none

\section{Acknowledgements}

The authors thank Giovanni Fanelli, Felicia Giacobbe, Alice Pellegrini, Margherita Serra, Saveria Tavoletta, Vito Leopoldo Troilo for the support given in database implementation. The authors thank Professor Luigi Cataliotti, President of Senonetwork Italia, for his constant and precious inspiration. 


\section{REFERENCES}

[1] Virnig BA, Tuttle TM, Shamliyan T, Kane RL - Ductal carcinoma in situ of the breast: a systematic review of incidence, treatment and outcomes. J Natl Cancer Inst 102 (2010) 170.

[2] Ernster VL, Ballard-Barbash R, Barlow WE, Zheng Y, Weaver DL, Cutter G,et al. - Detection of Ductal Carcinoma In Situ in Women Undergoing Screening Mammography. J Natl Cancer Inst 94(20) (2002) 1546-1554.

[3] AJCC Cancer Staging Manual, 8th edition, 2017, Springer, pag. 619.

[4] Wang W, Zhu W, Du F, Luo Y, Binghe X- The Demographic Features, Clinicopathological Characteristics and cancer specific outcomes for Patients with Microinvasive Breast Cancer: A SEER Database Analysis. Nature 7 (2017) 42045/DOI:10.1038

[5] American Joint Committe on Cancer. AJCC cancer staging manual. Philadelphia: LippincottRaven. 1997:172-173.

[6] Costarelli L, Campagna D, Mauri M, Fortunato L - Intraductal Proliferative Lesions of the Breast-Terminology and Biology Matter: Premalignant Lesions or Preinvasive Cancer? Int J Surg Oncol (2012], Article ID 501904

[7] Ferro A., Caldara A., Triolo R, Barbareschi M - Microinvasive breast cancer (Tmic): A descriptive mono-institutional report. J Clin Oncol 2008: 26, n. 15_suppl., abstract 11508

[8] Mori M, Tsugawa K, Yamauchi H, Yagata H, Ohde S, Soejima K et al. - Pathological assessment of microinvasive carcinoma of the breast. Breast Cancer 20(4) (2013) 331-335

[9] Matsen CB, Hirsch A, Eaton A, Stempel M, Heerdt A, Van Zee KJ et al. - Extent of microinvasion in ductal carcinoma in situ is not associated with sentinel lymph node metestases. Ann Surg Oncol 21 (2014) 3330-5.

[10] Yang M, Moriya T, Oguma M, De La Cruz C, Endoh M, Hishida T et al. - Microinvasive ductal carcinoma (T1mic) of the breast. The clinicopathological profile and immunohistochemical features of 28 cases. Pathol Int. 53(7) (2003) 422-8.

[11] Lyman GH, Giuliano AE, Somerfield MR, Benson AL III- American Society of Clinical Oncology Guideline Recommendations for Sentinel Lymph Node Biopsy in Early-Stage Breast Cancer. J Clin Oncol 23 (2005) 7703-20 
[12] Biganzoli L, Marotti L, Hart CD et al. Quality indicators in breast cancer care: an update from the EUSOMA working group. Eur J Cancer 86 (2017):59-81

[13] ACR BI-RADS ${ }^{\circledR}$ Atlas. 2013.

[14] European Guideline of Quality assurance in Breast Cancer Screening and Diagnosis. European Commission 2006

[15] Margalit DN, Sreedhara M, Chen YH, Catalano PJ, Nguyen PL, Golshan M et al. -. Microinvasive breast cancer: ER, PR, and HER-2/neu status and clinical outcomes after breastconserving therapy or mastectomy. Ann Surg Oncol. (2013) DOI 10.1245/s10434-012-2640-8

[16] Wang L, Arnold K - Mammography Frequently Detects Noninvasive Tumors. J Natl Cancer Inst 94(20) (2002) 1515

[17] Bianchi S, Vezzosi V - Microinvasive carcinoma of the breast. Pathol Oncol Res 14(2) (2008) $105-111$

[18] Intra M, Zurrida S, Maffini F, Sonzogni, Trifirò G, Gennari R et al. - Sentinel lymph node metastasis in microinvasive breast cancer. Ann Surg Oncol 10(10) (2003) 1160-5.

[19] Zavagno G, Belardinelli V, Marconato R, Carcoforo P, Franchini Z, Scalco G et al. - Sentinel lymph node metastases from mammary ductal carcinoma in situ with microinvasion. Breast 16(2) (2007) 146-151.

[20] de Mascarel I, MacGrogan G, Mathoulin-Pellissier S, Soubeyran I, Picot V, Coindre J-M Breast Ductal Carcinoma In Situ with Microinvasion. A Definition Supported by a Long-Term Study of 1248 Serially Sectioned Ductal Carcinomas. Cancer 94(8) (2002) 2136-2142

[21] Vieira CC, Mercado CL, Cangiarella JF, Moy L et al -. Microinvasive ductal carcinoma in situ: clinical presentation, imaging features, pathologic findings, and outcome. Eur J Radiol. 73 (2010) $102-107$

[22] Kwon JH, Kim YJ, Lee KW, et al. Triple negativity and young age as prognostic factors in lymph node-negative invasive ductal carcinoma of $1 \mathrm{~cm}$ or less. BMC Cancer. 10 (2010) 557.

[23] NCCN Guidelines version 1.2018, available at https://www.nccn.org/professionals/physician_gls/pdf/breast.pdf 
[24] Niu H-F, Wei L-J, Yu J-P, Lian Z, Zhao J, Wu Z-Z et al. - Is adjuvant chemotherapy necessary for patients with microinvasive breast cancer after surgery? Cancer Biol Med 13(1) (2016) 142-149

[25] Colleoni M, Rotmensz N, Peruzzotti G, Maisonneuve P, Viale G, Renne G et al. - Minimal and small size invasive breast cancer with no axillary lymph node involvement: the need for tailored adjuvant therapies. Ann Oncol 15 (2004) 1633-1639

[26] Guth AA, Mercado C, Roses DF, Darvishian F, Singh B, Cangiarella JF- Microinvasive Breast Cancer and the Role of Sentinel Node Biopsy: An Institutional Experience and Review of the Literature. Breast J 14 (4) (2008) 335-339.

[27] Zavotsky J, Hansen N, Brennan MB, Turner RR, Giuliano AE - Lymph Node Metastasis from Ductal Carcinoma In Situ with Microinvasion. Cancer 85(11) (1999) 2439-2443

[28] Lillemoe TJ, Tsai ML, Swenson KKRN, Susnik B, Krueger J, Harris K et al. Clinicopathologic analysis of a large series of microinvasive breast cancers. Breast J (2018) 1-6.

[29] Ko BS, Lim WS, Kim HJ, Yu JH, Won Lee J, Bum Kwan et S al. - Risk Factor for Axillary Lymph Node Metastases in Microinvasive Breast Cancer. Ann Surg Oncol 19 (2012) 212-216

[30] Prasad ML, Osborne MP, Giri DD, Hoda SA - Microinvasive Carcinoma (T1mic) of the Breast: Clinicopathologic Profile of 21 Cases. Am J Surg Pathol 24(3) (2000) 422-428

[31] Silva ATB, Castro F, Sousa JA, Silva S - Microinvasive Breast Carcinoma: An Institutional Case Series. J Am Coll Surg (2017) e156

[32] Katz A, Gage I, Evans S, Shaffer M, Fleury T, Smith FP et al. - Sentinel lymph node positivity of patients with ductal carcinoma in situ or microinvasive breast cancer. Am J Surg 191 (2006) 761766

[33] Klauber-DeMore N, Tan LK, Liberman L, Kaptain S, Fey J, Borgen P et al. - Sentinel Lymph Node Biopsy: Is It Indicated in Patients With High-Risk Ductal Carcinoma-In-Situ and Ductal Carcinoma-In-Situ With Microinvasion? Ann Surg Oncol 7(9) 2000 636-642

[34] Sakr R, Barranger E, Antoine M, Prugnolle H, Darai E, Uzan S - Ductal Carcinoma In Situ: Value of Sentinel Lymph Node Biopsy. J Surg Oncol 94 (2006) 426-430 
[35] Shatat L, Gloyeske N, Madan R, O'Neil M, Tawfik O, Fan F - Microinvasive breast carcinoma carries an excellent prognosis regardless of the tumor characteristics. Hum Pathol 44 (2013) 26842689

[36] Silver SA, Tavassoli FA - Mammary Ductal Carcinoma In Situ with Microinvasion. Cancer 82(12) (1998) 2382-2390

[37] Kim M, Kim HJ, Chung YR, Kang E, Kim E-K, Kim SH et al. - Microinvasive carcinoma versus ductal carcinoma in Situ: a comparison of clinicopathological features and clinical outcomes. J Breast Cancer 2(2) (2016) 197-205

[38] Orzalesi L, Casella D, Criscenti V et al. Microinvasive breast cancer. Pathological parameter, cancer subtypes distribution, and correlation with axillary lymph nodes invasion. Results of a large single-institution series. Breast Cancer 23 (2016):640-648 